\title{
CHANGES IN THE OPTICAL PROPERTIES OF HEMP OFFICE PAPERS DUE TO ACCELERATED AGEING
}

\author{
Ivana Plazonić (D), Lahorka Malnar (D), Vesna Džimbeg-Malčić \\ Željka Barbarić-Mikočević (D), Irena Bates (D) \\ University of Zagreb, Faculty of Graphic Arts, Zagreb, Croatia
}

\begin{abstract}
This research observes alteration in optical properties of two commercially available hemp office papers exposed to various methods of accelerated ageing. Both handmade office papers, natural colored and non-chlorine bleached were formed from 100\% hemp plant fiber. In order to establish their optical stability under controlled conditions two different accelerating ageing treatments were carried out for the period of 24 hours as a simulation of different degradation processes that naturally occurs in cellulosic materials: thermal oxidation (TO) and photo-oxidation (PO). Before and after ageing treatments the changes in the optical properties of papers were monitored by X-rite DTP 20 spectrophotometer and obtained differences in Reflectance index (R), Euclidean difference ( $\left.\triangle E_{00^{*}}\right)$ and Yellowness Index (YI E313) have been discussed. The results have shown how the paper optical stability is dependent upon manufacturing process. Namely, it was found that bleached hemp pulp provide better optical stability of papers than unbleached hemp pulp.
\end{abstract}

Key words: accelerated ageing, hemp fiber, office papers, optical properties

\section{INTRODUCTION}

Behavior of paper as a multi-component material is strongly dependent upon the nature, origin and characteristics of its each component as well as upon their interactions (Area, 2011). The paper components can be classified according to their origin, chemical structure and function such as: fibers (composed mainly of cellulose, but also of lignin, hemicelluloses and other minor components), mineral particles (talc, kaolin, calcium carbonate, etc.), natural sizing agents (as starch or rosin) or synthetic ones (as alkyl ketene dimer (AKD) and alkenyl succinic anhydride (ASA)), colorants and other substances (Area, 2011). From the moment of its formation, paper suffers deterioration due to endogenous ( $\mathrm{pH}$, metal ions, lignin, degradation products) and exogenous (heat, humidity, light, oxygen, pollutant gases) contributors (Area, 2011; Strlič et al, 2004). However, heat and moisture are considered as two of the most important environmental influences on the stability of papers e.g. yellowing and loss of strength (Karlovits et al, 2012). From the viewpoint of the paper industry ageing are irreversible changes that occur slowly over time and in paper substrate ageing process results with the deterioration of useful properties that can render it unsuitable for its primary usage. Therefore, an accelerated ageing test is a practical way to predict the physical and chemical changes occurring naturally in a paper in a relatively short period. In a practice, a numerous accelerated ageing tests with various aging conditions are used for evaluation and ranking paper substrates on their permanence. Some of the standard techniques of accelerated ageing are moist-heat $\left(80{ }^{\circ} \mathrm{C}\right.$ and $\left.65 \% \mathrm{RH}\right)$, dry-heat $\left(105^{\circ} \mathrm{C}\right.$ ) and treatment with a xenon arc lamp (Karlovits et al, 2012). The concept of accelerated ageing test is simple. Namely, the rate of most chemical reactions in a paper sample increases when temperature is increased and those chemical changes affecting the physical properties of a paper. Paper optical stability is extremely important in graphic industry because it contribute, more than any other factor, to the overall paper appearance and appeal (Thompson, 2004). As a result of paper ageing, optical properties are significantly changed (Jääskeläinen et al, 2007). The optical properties of the paper are very sensitive to its structure. Cellulose is the major structural component of paper. Pure cellulose absorbs visible light only to a small extent (380 -550 nm), while absorption in near UV spectral region (300 $-380 \mathrm{~nm}$ ) is more pronounced. It is therefore in that spectral range most of the damage in cellulose is induced during exposure to electromagnetic radiation (Strlič et al, 2004). It is proven how the type and quality of the raw material is crucial for the longevity of the product. Namely, already degraded recycled fibers will lead to a less durable paper than high-quality virgin fibers, especially cotton ones (Strlič el at, 2004). Other components of paper also influence its stability, the major one being another natural polymer, lignin with high capacity to absorb ultraviolet light (absorption maximum at wavelength of $200-210 \mathrm{~nm}$ and at 270-280 nm) (Jingjing, 2011). Many other organic and inorganic components in the paper network structure (such as fillers, adhesives, pigments, binders, etc.) strongly influence on the paper optical stability as well. In general, the brightness $(B)$, the lightness $\left(L^{*}\right)$ of the $C I E L^{*} a^{*} b^{*}$ color system and the whiteness 
(W) of paper decline, while the yellowness and the $b^{*}$ (shift to yellow) and a* (shift to red) coordinates of the CIEL*a*b* 20 color system increase after exposing to accelerated ageing.

\section{MATERIALS AND METHODS}

\subsection{Materials}

\subsubsection{Hemp office paper}

In this research two commercially available hemp office papers (grammage $90 \mathrm{gm}^{-2}$ ) were used as samples:

Natural hemp paper - handmade sustainable paper made from 100\% hemp plant fiber with wildgrass is unbleached, uncoated printer-compatible (Laser and Inkjet) paper in natural color with natural deckled edge. Paper manufacturer is Distant Village, US.

Bleached hemp paper - handmade sustainable paper made from 100\% hemp plant fiber is non-chlorine bleached uncoated printer-compatible Laser and Inkjet) paper in cream color with natural deckled edge. Paper manufacturer is Distant Village, US.

\subsection{Methods}

\subsubsection{Aging Treatments}

In order to obtain optical stability of hemp containing papers under controlled degradation levels, two different accelerating ageing treatments were carried out as a simulation of different degradation processes that naturally occurs in cellulosic materials.

- Thermal oxidation: it was carried out on all laboratory formed papers at $60^{\circ} \mathrm{C}$ in oven for 24 hours in absence of light. It is well known that thermal oxidation induces the breakage of chemical bonds in cellulose and the formation of carbonyl, carboxyl, and hydroperoxide groups (Cocca et al., 2011).

- Photo-oxidation: papers were exposed in a Cofomegra Solarbox 1500e Xenon Test Chamber with a Xenon light source for 24 hours. Irradiation was kept at a constant power of $550 \mathrm{~W} / \mathrm{m}^{2}$ and at a temperature of $60^{\circ} \mathrm{C}$. Photooxidative reactions result in an increase of carbonyl content, carboxyl, and hydroperoxide groups (Cocca et al., 2011).

\subsubsection{Optical Properties Analysis}

Characterization of accelerate aged paper samples was discussed through optical properties analysis (Reflectance index, Euclidean difference and Yellowness Index) and compared to unaged (control) paper samples. Monitored optical measurements were repeated 20 times on each paper.

\section{- $\underline{\text { Reflectance index (R) }}$}

Papers reflectance spectra measurements were processed using X-rite spectrophotometer with standard illuminant D65 and 2-degree observer, in the interval of the wavelengths from $400 \mathrm{~nm}$ to $700 \mathrm{~nm}$ for every $10 \mathrm{~nm}$. Reflectance spectra values (R) were measured for all paper samples before ageing (Runaged) and after accelerated ageing (Raged) and gained results are presented as $\Delta R$ according to Equation (1):

$\Delta \mathrm{R}=R_{\text {unaged }}-R_{\text {aged }}$

\section{- The colour differences or Euclidean difference $\left(\Delta \mathrm{E}_{00}{ }^{*}\right)$}

Colorimetric CIE L*a*b* values of all laboratory papers before and after accelerated ageing were carried out by means of X-rite spectrophotometer. Color data were calculated under illuminant D65 (daylight $\left.6500^{\circ} \mathrm{K}\right), 2$ standard observers, sphere geometry, specular component included, and UV energy included. The instrument was calibrated against a white standard tile. In the CIE L*a*b* color space the value L* represents the lightness of the color and the value $+a^{*}$ represents redness or the value $-a^{*}$ represents greenness, and the $+b^{*}$ value represents yellowness or the value $-b^{*}$ represents blueness (Kipphan, 2001). The color differences or Euclidean difference $\left(\Delta \mathrm{E}_{00^{*}}\right)$ of all analyzed paper substrates were calculated with the following equation (Luo, 2001), using the corresponding starting material (unaged paper substrate) as reference: 
$\Delta E_{00}^{*}=\left(\frac{\Delta L^{\prime}}{k_{L} S_{L}}\right)^{2}+\left(\frac{\Delta C^{\prime}}{k_{C} S_{C}}\right)^{2}+\left(\frac{\Delta H^{\prime}}{k_{H} S_{H}}\right)^{2}+R_{T} \frac{\Delta C^{\prime}}{k_{C} S_{C}} \frac{\Delta H^{\prime}}{k_{H} S_{H}}$

- Yellowness index (YI E313)

The Yellowness Index (paper discoloration) is an indication of the degree to which a specimen surface is different to the ideal white in the yellow direction. In this research, it is used to indicate the influence of a two different accelerating ageing treatments on the change of straw-containing paper color during ageing. The measurements were performed in accordance with ASTM Method 313 (YI E313) by spectrophotometer X-Rite DTP 20 at D65/2‥ On each paper sample, on different locations, 10 values were measured. Yellowness index according to the ASTM Method E313 is calculated as follows:

$Y I E 313=\frac{100 \times\left(C_{x} X-C_{z} Z\right)}{Y}$

where $X, Y, Z$ are the $C$ IE trismuilus values, $C_{x}$ and $C_{z}$ are coefficients (D65/2o: $C_{x}=1.2985, C_{z}=1.1335$ ) (Hunter Associates Laboratory, 2008).

\section{RESULTS}

The changes in the optical stability of hemp office papers after exposing to accelerated ageing were analyzed and experimental results are presented at Figures 1-5.

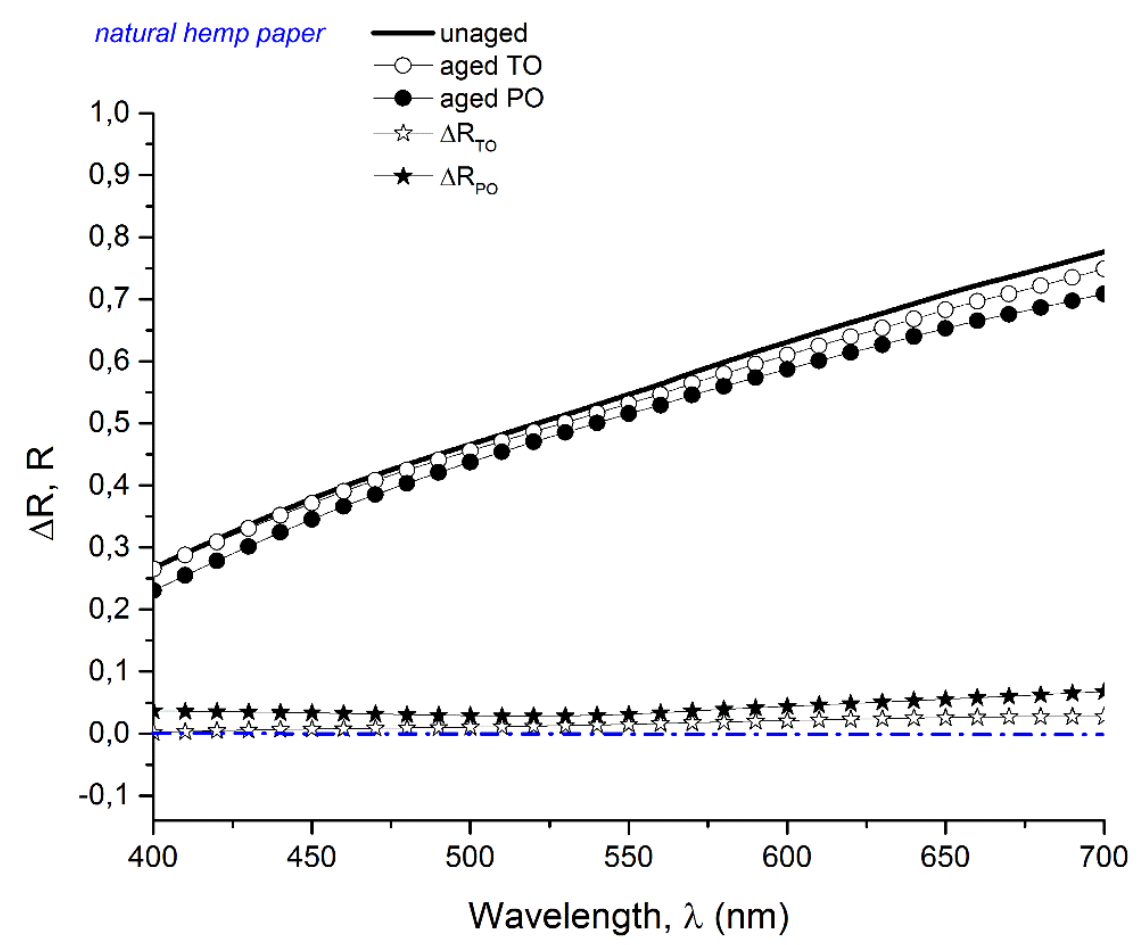

Figure 1: The impact of accelerated ageing on natural hemp paper reflectance 


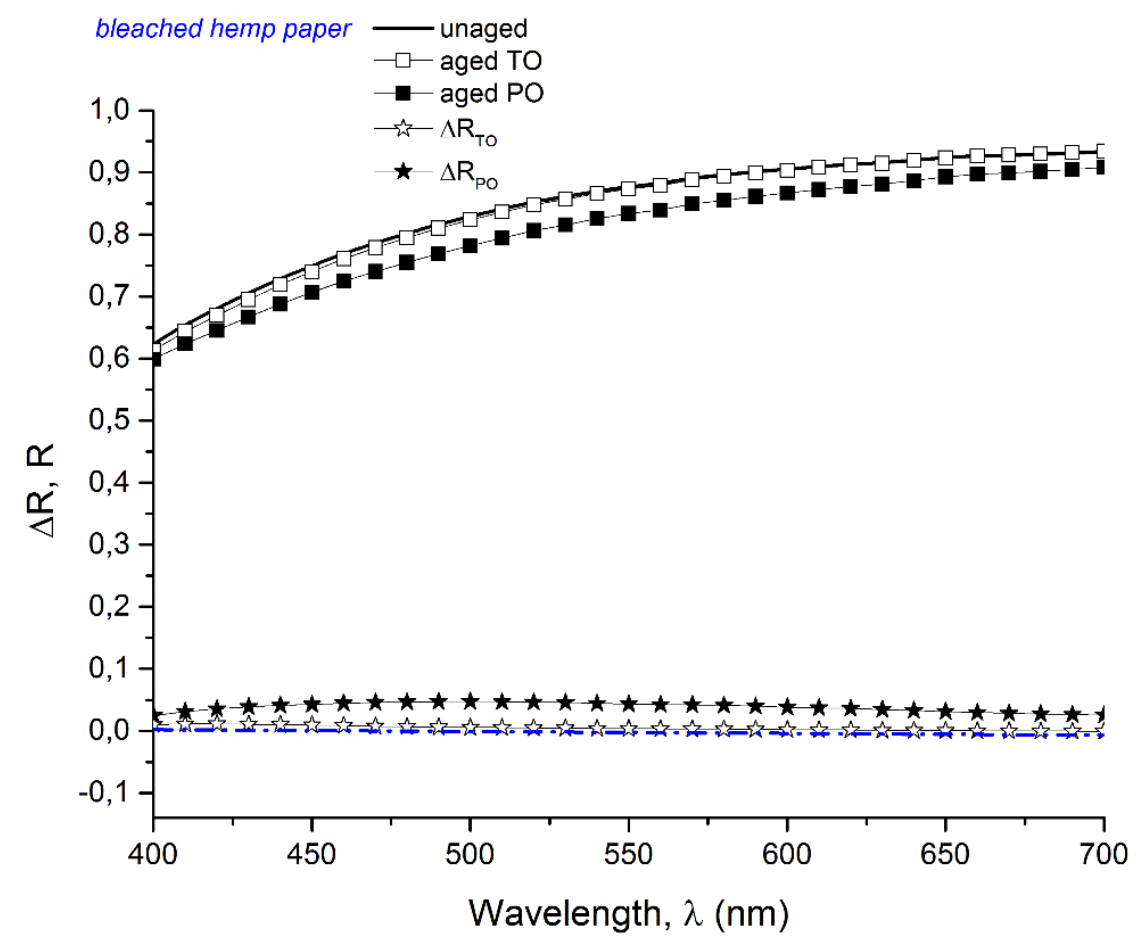

Figure 2: The impact of accelerated ageing on bleached hemp paper reflectance

From Figures 1 and 2 it is visible that both hemp office papers (natural and bleached) show more noticeable changes in reflectance values after exposure to UV/VIS radiation by xenon lamp (PO) compared to those aged only by thermal oxidation (TO). All examined hemp papers substrates after TO and PO ageing treatment have shown similar deviations in whole spectrum. For better observing and comparing changes on both analyzed papers, relative changes of reflectance $(\Delta R /$ Runaged $)$ are summarized at Figure 3.

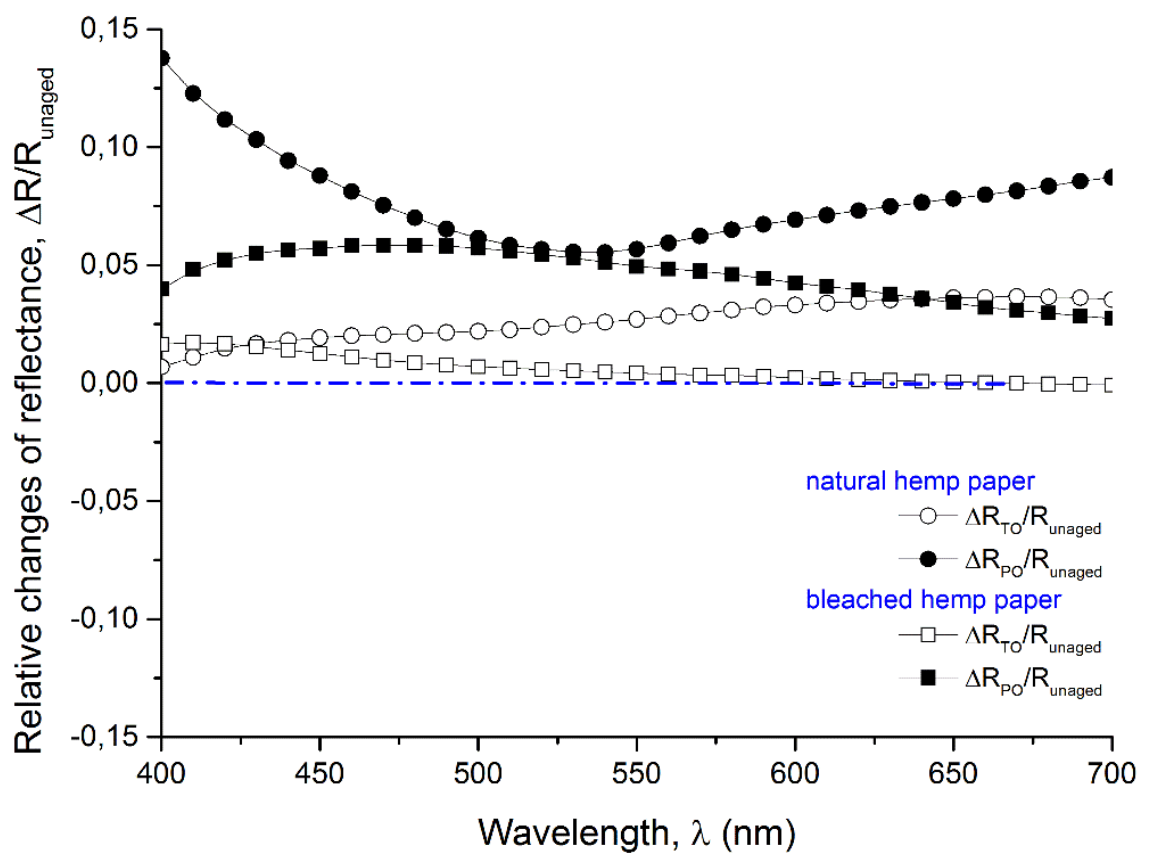

Figure 3: The relative changes of the reflectance of the hemp papers after ageing depending on ageing method

From relative changes of the reflectance values, we can see that maximum difference is achieved in blue $(400-460 \mathrm{~nm})$ and red part $(620-700 \mathrm{~nm})$ of spectrum for natural hemp papers, while for bleached hemp papers max $\Delta R / R_{\text {unaged }}$ is on $500 \mathrm{~nm}$. The treatment with a xenon lamp (PO) had the strongest influence on natural hemp papers, where difference in the red part of the spectrum have reached $8.7 \%$ and in blue part $13.8 \%$. Recorded maximum relative changes of reflectance for bleached hemp paper was $5.8 \%$ at wavelength $500 \mathrm{~nm}$. 


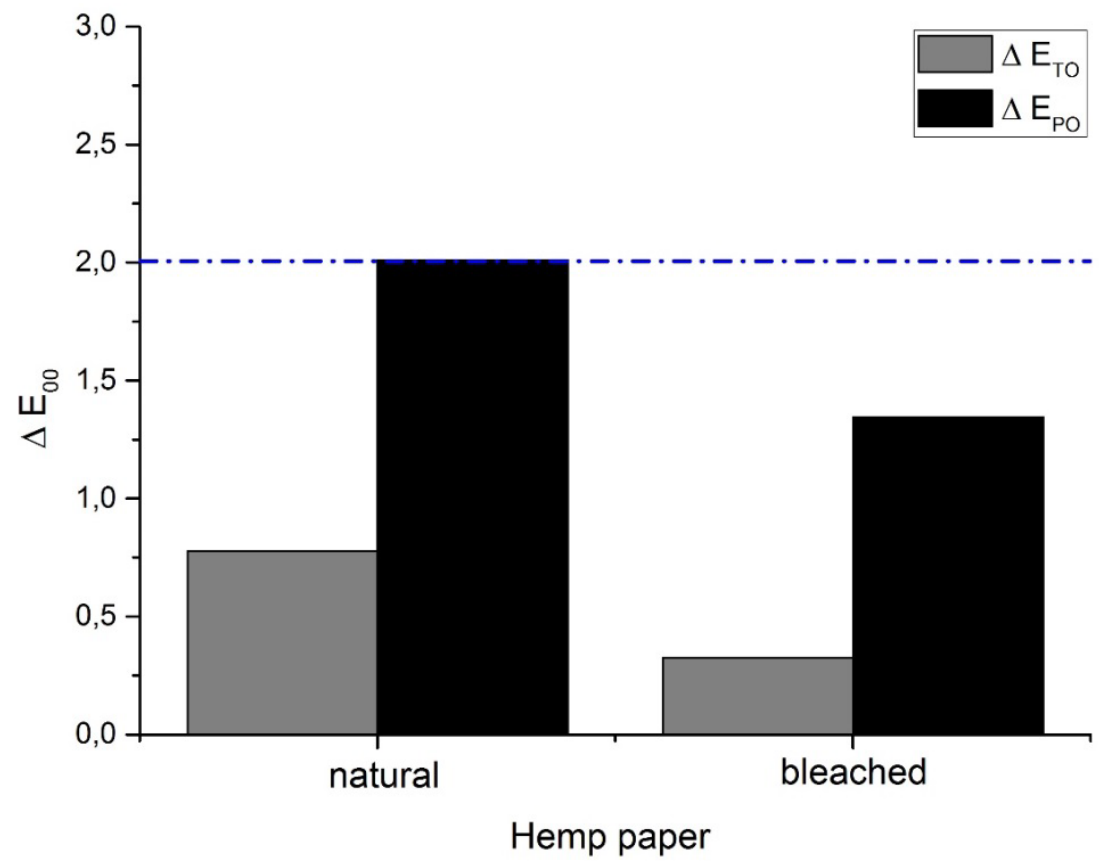

Figure 4: Euclidean difference

The calculated color differences or Euclidean difference $\left(\Delta \mathrm{E}_{00} *\right)$ values by equation 2 are presented at Figure 4. Color difference values caused by thermal-oxidation (TO) ageing are minor (from 0.32 to 0.78 ), while the color differences values are up to 2.01 for natural hemp paper aged by photo-oxidation (PO). Namely, according to tolerance definition $\Delta \mathrm{E}_{00}{ }^{*} \leq 2$ is classified as very small noticeable difference for standard observer while $\Delta \mathrm{E}_{00}{ }^{*}=5$ is big noticeable difference in the color whose standard observer can recognized (Zjakić, 2007). From these results it is evident that office paper formed from bleached hemp pulp exhibits better optical stability to artificial ageing (by thermal-oxidation and by photo-oxidation) than papers formed from natural unbleached pulp.

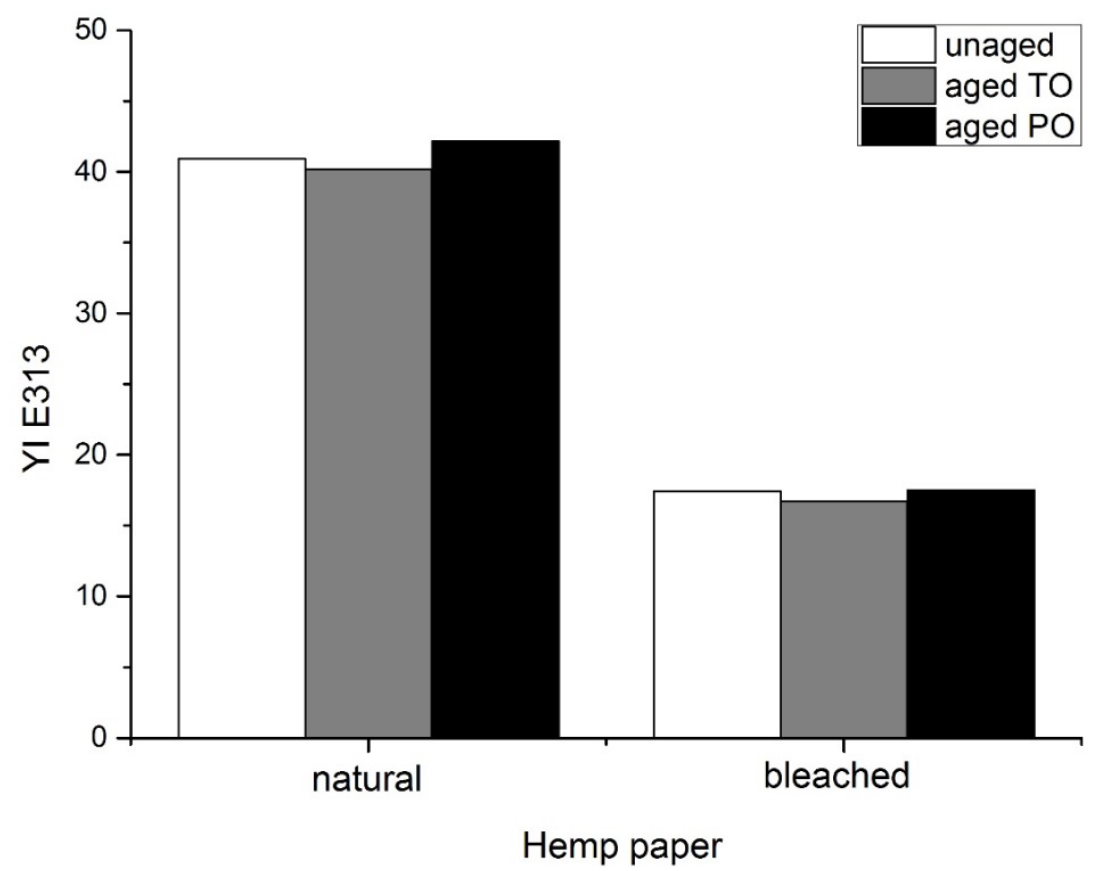

Figure 5: Yellowness Index 
Figure 5 shows the influence of two accelerated ageing techniques (thermal and photo-oxidation treatment with a xenon lamp) on the Yellowness Index of the papers.

The tested papers differ significantly in yellowness (natural hemp paper: YI E313 $=40.9$, bleached hemp paper: YI E313 = 17.4), the values confirm expected that natural hemp paper is more yellowish than bleached hemp paper. After 24 hours of treatment with heat and a xenon lamp, the results indicate that bleached hemp paper yellowed more slowly than natural hemp paper. Paper discoloration for both analyzed types of hemp paper (natural and bleached) due thermal-oxidation is not noticed.

\section{DISCUSSION}

Generally, paper as lignocellulose material undergo light-induced yellowing. Most responsible component for paper photo yellowing is lignin which contains numerous chromophores that efficiently absorb UV radiation. The mechanism of lignin photo-oxidation can be described as follows: primary chromophores from lignin absorb the light with 300 to $400 \mathrm{~nm}$ wavelengths $\rightarrow$ break of etheric bonds and creation of free radicals $\rightarrow$ reaction between free radicals and lignin $\rightarrow$ formation of ketyl radicals $\rightarrow$ phenoxy and ketone radicals $\rightarrow$ production of yellow quinone and chromophores with secondary chromophores $\rightarrow$ lightinduced destruction of lignin and yellowing of paper (Nemati et al., 2011). Therefore, to remove the residual lignin and chromophores inside the pulp is a main purpose of bleaching the pulp. $50 \%$ of bleached mechanical pulps are currently produced using dithionite (hydrosulfite) bleaching which react with the chromophores present in the lignin of pulp to make less colored compounds, and consequently to give a brighter aspect to the pulp (El-Sakhawy, 2005). As both office papers analyzed in this study were handmade, from $100 \%$ hemp plant fiber it is to be expected that in some percentage they contain lignin. Lignin content in hemp fiber is usually 2-5\% (Thomsen et al., 2005.). Bleaching process have made optical properties of hemp paper more stable due accelerated ageing comparing to those papers made from natural unbleached hemp fibers.

\section{CONCLUSIONS}

The effect of accelerated ageing on hemp office papers optical stability was studied. Taking into account all obtained results, the following could be concluded:

- Exposure to a xenon light source for 24 hours causes more rapidly yellowing of both papers than exposure to heat influence.

- The changes in optical properties due to accelerated ageing are more pronounced for the unbleached hemp office papers but still standard observer cannot recognize it.

\section{REFERENCES}

[1] Area, M.-C., Cheradame, H.: "Paper aging and degradation: recent findings and research methods", BioResources 6(4), 5307-5337, 2011.

[2] Cocca, M., D’Arienzo, L., D’Orazio, L.: "Effects of Different Artificial Agings on Structure and Properties of Whatman Paper Samples", ISRN Materials Science, 7, 2011. doi:10.5402/2011/863083.

[3] El-Sakhawy, M.: "Effect of bleaching sequence on paper ageing", Polymer Degradation and Stability 87, 419-423, 2005. doi: 10.1016/j.polymdegradstab.2004.10.002.

[4] Hunter Associates Laboratory, Inc.: "Yellowness Indices", Insight on Color 8(15), 2, 2008.

[5] Jääskeläinen, A-S., Liitiä, T.: "UV/VIS reflectance spectroscopy reveals the changes in fibre chemistry during ageing", SpectroscopyEurope 19 (5), 11-13, 2007.

[6] Jingjing, L.: "Isolation of lignin from wood", BSc thesis, Saimaa University of Applied Sciences, 2011.

[7] Karlovits, M., Gregor-Svetec, D.: "Durability of Cellulose and Synthetic Papers Exposed to Various Methods of Accelerated Ageing", Acta Polytechnica Hungarica 9 (6), 81-100, 2012.

[8] Kipphan, H.: "Handbook of Print Media", (Springer, Verlag, 2001.).

[9] Luo, M. R., Cui, G., Rigg, B.: "The development of the CIE 2000 colour difference formula: CIEDE2000", Color Research \& Application 26 (5), 340-350, 2001. doi:10.1002/col.1049.

[10] Nemati, M., Hemmasi, A. H., Talaeipour, M., Samariha, A.: "Studying the effect of photo-yellowing on the brightness property of chemi-mechanical pulping paper", Cellulose Chemistry and Technology 47(12), 93-109, 2013. 
[11] Strlič, M., Kolar, J.: "Ageing and stabilisation of paper", (National and University Library, Ljubljana, 2004.), page 211.

[12] Thompson, B.: "Printing Materials: Science and Technology", (Pira International, Leatherhead, 2004.), page 591.

[13] Thomsen, A. B., Rasmussen, S. K., Bohn, V., Nielsen, K. V., Thygesen, A.: "Hemp raw materials: The effect of cultivar, growth conditions and pretreatment on the chemical composition of the fibres", Forskningscenter Risoe, 1507, 30, 2005.

[14] Zjakić, I.: "Upravljanje kvalitetom ofsetnog tiska", (Hrvatska sveučilišna naklada, Zagreb, 2007.), page 245.

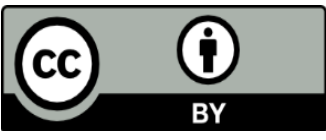

(C) 2018 Authors. Published by the University of Novi Sad, Faculty of Technical Sciences, Department of Graphic Engineering and Design. This article is an open access article distributed under the terms and conditions of the Creative Commons Attribution license 3.0 Serbia (http://creativecommons.org/licenses/by/3.0/rs/). 